\title{
A Domain-Specific Modelling Language for Corporate Social Responsibility (CSR)
}

\begin{abstract}
Corporate Social Responsibility (CSR) has become a strategic critical subject in many business processes, since enterprises not only need to provide good products or services, but they also have to demonstrate that they are environmentally and socially responsible. In this context, enterprises should use appropriate computer systems in order to manage CSR ensuring the adoption of best practices with the aim of obtaining competitive advantages. On the other hand, Model-Driven Engineering is a proven and accepted paradigm that provides sound mechanisms to develop quality and reliable computer systems in an efficient way starting from business models. The main results presented in this paper are a CSR Metamodel and a CSR UML Profile that provide a DomainSpecific Modelling Language (DSML) to represent CSR. This DSML supports the design of CSR Computer Independent Models (CIM) that are the starting point for Model-Driven Engineering development. To propose this DSML to represent CSR we analysed international standards, guides and regulations on CSR and we reviewed CSR strategies developed by different companies in order to define the artifacts of the CSR Metamodel. Finally, a practical case study using this DSML is provided in order to improve and to validate the defined CSR Metamodel, and to show how to apply the proposal in an actual company. Keywords: Model-Driven Engineering, Enterprise Modelling, Domain-Specific Modelling Language, Metamodel, UML Profile, Corporate Social Responsibility
\end{abstract}

Preprint submitted to Computers in Industry 


\section{Highlights}

- Analysis of CSR standards and regulations to identify CSR management requirements.

- Use of a method of work for CSR requirements elicitation and the metamodel definition.

- Definition of a CSR Metamodel and a CSR UML Profile to provide a DSML for CSR.

- Use of a case study to validate and to show how to apply the proposed DSML for CSR.

\section{Introduction}

Corporate Social Responsibility (CSR) implies that managers must be responsible for the consequences of their actions not only in front of stakeholders but also in front of society [1. This idea has gained importance in recent years and it has become a need for enterprises beyond a competitive advantage [2].

Many factors contribute to this increasing demand. First, governmental organisations are working on mandatory policies, regulations and reporting regarding sustainability, human rights and ecological commitments [3]. Moreover, an increasing social pressure regarding ecological, ethical and sustainable behaviours drives companies to initiate or improve actions in the field of CSR with more or less success 4 . Finally, studies that show how companies improve their results by implementing CSR actions and policies [5] encourage other companies to include actions in its company's strategy.

As a consequence, enterprises all over the world are concerned with the management and disclosure of their actions on CSR considering many standards and regulations that international organisations publish and promote [6, 7, 8. However, enterprises usually apply ad hoc processes integrated with their control 
management systems [9] or connect CSR results with quality management indicators [10], but they generally do not use specific computer systems to manage CSR.

Information systems and ICT must be continuously aligned with the CSR strategy in order to provide the necessary technological support to accomplish regulations and to manage CSR processes and actions efficiently [5, 11. ModelDriven Engineering (MDE) is a way to produce software which tries to establish links between conceptual and technological levels, not only with approaches like the OMG's proposal Model Driven Architecture (MDA) [12, but also as Grammarware [13] and others [14]. The application of MDE [15] to implement CSR Computer Systems could provide advantages such as, for example, a more efficient way to develop a computer system, or the capability to incorporate 40 new requirements from the conceptual level where users are more comfortable performing enterprise models [16].

In this field, there are a lot of Enterprise Modelling Languages suitable to model enterprise dimensions like processes, product, organisation or decisions at conceptual level [17, 18. There are also other initiatives such as Unified

45 Enterprise Modelling Language (UEML) which tries to make these languages more interoperable [19. However, there is no specific modelling language to represent CSR, although some researchers agree that CSR is a key issue which should be modelled in the same way as other enterprise dimensions in order to obtain some of the benefits of MDE [20] as for instance, advantages for interoperability and portability [21, 22, 23].

Therefore, it would be useful to define a Domain-Specific Modelling Language (DSML) to develop enterprise models focused on the CSR dimension. This DSML would be suitable for: (1) representing how enterprises currently manage CSR; (2) identifying what CSR improvements are needed in business 55 reengineering projects; and (3) applying MDA to implement computer systems to manage CSR actions and information in an integrated way.

The research work presented in this paper, jointly with the proposal of an Agile Model-Driven Methodology to guide the implementation of CSR Computer 
Systems, are the two phases included in the project we carried out to define a Model-Driven CSR Framework [20]. The methodology enables the application of Model-Driven Engineering to generate CSR Computer Systems. The definition of the CSR Metamodel, described in this paper, provides a Domain-Specific Modelling Language for CSR (DSML4CSR) that can be used to develop models at conceptual level and apply the aforementioned methodology.

Regarding the method of work used in this stage of the project, we applied a systematic proposal to identify strategic requirements [24] that was conducted out by means of a review of the domain. Therefore, we analysed some recognised international standards on CSR 6, 7, 8, newer research works in CSR and current practices on CSR management in actual companies, in order to identify the concepts of this metamodel.

The paper is organised as follows. Section 2 describes a literature review focused on Model Driven Engineering as a paradigm useful to develop computer systems from business models and metamodelling background. Section 3 shows the method of work used to conduct the research presented in this paper.

75 Section 4 collects the domain analysis performed in order to obtain the requirements for the metamodel. In Section 5, we define a CSR Conceptual Map to understand the requirements, the CSR Metamodel and the CSR UML Profile in order to implement th DSML4CSR. Finally, Section 6 outlines the final step of the method of work showing a case study as a proof of concept for the validation of the CSR Metamodel, and Section 7 outlines the main conclusions of the research.

\section{Literature review}

\subsection{Model-Driven Engineering}

Model-Driven Engineering (MDE) is a software development paradigm that 85 can be useful to develop integrated computer information systems [25, 26, 27. The main objective of this paradigm is to promote the use of models and their transformations in order to generate maintainable software that can easily in- 
corporate new requirements and evolve at the same time as new needs arise [15].

MDE principles are implemented by the Object Management Group (OMG) [28 by means of the Model Driven Architecture (MDA) [12 around a set of OMG standards such as MOF, XMI, OCL, UML, etc. Other proposals like Microsoft Domain-Specific Language tools (MS/DSL) [29] or Eclipse Modeling Framework (EMF) 30] are based on the same MDE principles, but they provide different standards and technical spaces to generate software from models 31. Despite, all these proposals, in [32] it is stated that MDE is not well applied in industry since there is no general purpose tools.

MDA suggests a framework that defines models at three levels of abstraction: Computation Independent Model (CIM), Platform Independent Model (PIM), and Platform Specific Model (PSM). These models are obtained by successive transformations from CIM to PIM and, from PIM to PSM. As it is demonstrated, this approach improves portability, interoperability and reusability through architectural separation of concerns [12. Particularly, these advantages are more interesting when we want to generate software from enterprise CIM models [33].

Therefore, the task of developing enterprise models has more benefits than just those derived from the definition of Vernadat [18, that defines Enterprise Modelling (EM) as the art of externalising enterprise knowledge with several purposes. Examples of these benefits are supporting computer systems development, providing understanding to apply business processes re-engineering, and enabling better analysis of information and workflows among others.

Enterprise Modelling Languages (EML) allow engineers to develop models to represent the enterprise from different points of view such as organisational perspective, processes, decisions, product, information, etc. In this context, some 115 initiatives, as for example GRAI [34] or CIMOSA [35, were carried out around the $80 \mathrm{~s}$ in order to provide suitable EMLs to model enterprises at conceptual level, which could be considered as CIM models into the MDA domain [36].

Other research works based on the aforementioned EMLs, such as UEML 
[19, 37] or $\mathrm{POP}^{*}$ [38, 39], have performed an effort to make EMLs more interopwith different EMLs.

On the other hand, the Engelsman's proposal [40, based on the existing standard for enterprise modelling: the ArchiMate [41, provides a modelling language focused on a specific field. Its objective is to model high-level goals CSR needs regarding goals and allows to represent stakeholders concerns and assessments, there are CSR aspects that cannot be explicitly represented. The objective of the work included in this paper is to provide a specific representation tool, closer to the business people that manage CSR, focused not only on goals, but also on processes, information, stakeholders, policies and all the key issues that CSR management requires.

Although the business research community defines theoretical and business CSR models 42 and frameworks that are useful to suggest ways or patterns to perform CSR management, there are no proposals in the context of EMLs that allow to represent CSR conceptual models as they are needed for MDA application [20].

A specific EML for CSR should provide artifacts and an adequate semantic and a syntax to represent the components and behaviour of this new asset. Therefore, it would be useful to define a Domain-Specific Modelling Language

(DSML) 32 for CSR modelling and, taking into account the fundamentals of the modelling languages, the first step would be to define a metamodel which could identify relevant concepts and their relationships regarding the CSR domain and management 25].

\subsection{Metamodelling for specific domains}

145

Models need to be expressed in a modelling language, (for example UML for design models or programming languages for source code models) if we aim to transform models following MDA. Metamodels are the way which the syntax and semantics of these modelling languages are expressed [43, 44]. 
In this context, a metamodel can make statements (some expression about the system under study that can be considered true or false) about what can be expressed in the valid models of a certain modelling language [45]; or a metamodel can also be defined as a model of a language of models [14. Therefore, a metamodel defines a modelling language, and the instances of a metamodel are models of that modelling language.

OMG 28] defines four layers of abstraction for metamodelling in MOF proposal: the Meta-Metamodel layer (M3), with metamodelling languages like MOF and Ecore; the Metamodel layer (M2), where the metamodels of languages are defined using metamodelling languages from M3; the Model layer (M1), with the specific models defined from those metamodels in M2; and the User Objects layer (M0), with the concrete objects of a system as instances of models in M1. However, there are several available alternatives in metamodelling languages, such as Ecore, MOF and Graph, Object, Property, Relationship, and Role (GOPRR) [46. In this research work, the MDA framework has been chosen in order to define the CSR Metamodel.

On the other hand, UML provides the mechanism of the profiles that can be useful to extend the UML language itself and provide a DSML. In this sense, some initiatives based on UML for modelling different enterprise dimensions have been developed providing a DSML that allows performing specific enterprise models on these dimensions [47]. In particular, there are some implementations derived from UEML and POP* Metamodels, such as Unified Enterprise Competence Modelling Language (UECML) 48, or 'UML2 Profile for Enterprise Knowledge' 49, devoted to competence based enterprise modelling or modelling enterprise knowledge respectively. There are other studies nonUEML based, as for example [50, in which a metamodel is used to maintain traceability of requirements of data warehouse from CIM to PIM.

A UML profile to represent safety-related concepts, based on regulations and international standards is showed in [51]. This UML profile defines a DSML that allows software engineers to develop safety-related specific models. The authors show how this profile facilitates the communication among all the stakeholders 

aerospace systems.

Further research in the health domain, in particular in HL7 standards as presented in [52], defines a solution in order to support software engineers for modelling real problems in UML and then to transform into HL7 Models.

Regarding CSR domain, there are proposals to model CSR as for instance [53]. This research work provides a conceptual framework to analyse the integration and maturity of one enterprise regarding CSR issues, however it does not provide a modelling language for this specific domain. Other works, like the research shown in [54] presents the analysis of usefulness of diverse modelling methods for sustainable development but not a DSML to model CSR.

In conclusion, the previous experiences show how MDA can be useful to reduce development time and identify possible errors or inconsistencies in early phases of computer system development. MDA application requires design of enterprise models at CIM level, and in this context a DSML can provide a success key issue. Moreover, a DSML for CSR modelling could improve the results and the interaction among all the stakeholders participating in the development of the CSR Computer System in the early stages of the project.

\section{Method of work}

In this section we describe the research work performed and the method of work we adopted to develop the final DSML4CSR proposed.

Aiming to propose a metamodel that allows to define a DSML to develop CSR models, we needed to identify which concepts must be included as artifacts in that metamodel. Consequently, the first step was to identify data and functional requirements to manage CSR. In order to achieve this partial goal

we adapted an empirical method of work taking into account research proposals and formal methods and techniques for requirements elicitation.

To define the steps and techniques used in our research we considered and reviewed: (1) formal methods and techniques for requirements elicitation as best 
practices identification and benchmarking [55, 56]; (2) research works regarding research methods as for instance 24] where the authors propose a process to define requirements focused on enterprise goals. This proposal is suitable to identify requirements for strategic issues, and CSR is considered a strategic concern for companies [57; and (3) the results of some of our previous research works which focused on defining enterprise requirements [58, 59].

In particular, we improved the process defined by 24 including specific steps of requirements elicitation and an Action Research approach 60 used in some of our previous research works. First of all, we develop a domain analysis considering standards and regulations, research results in CSR and also, the analysis of current practices in a set of companies. Then, we analysed the results and developed a conceptual map to clarify the concepts. This conceptual map set the basis to develop the metamodel and the UML profile. The steps and activities we followed to obtain the results presented in this paper were (see Figure 1):

1. Domain analysis and to analyse current practices, specific items and concepts used by these companies.
- Data interpretation: identification and organisation of the data results obtained from previous domain review that are considered the CSR requirements. nies that already develop CSR management and disclosure to identify

2. Proposal development 


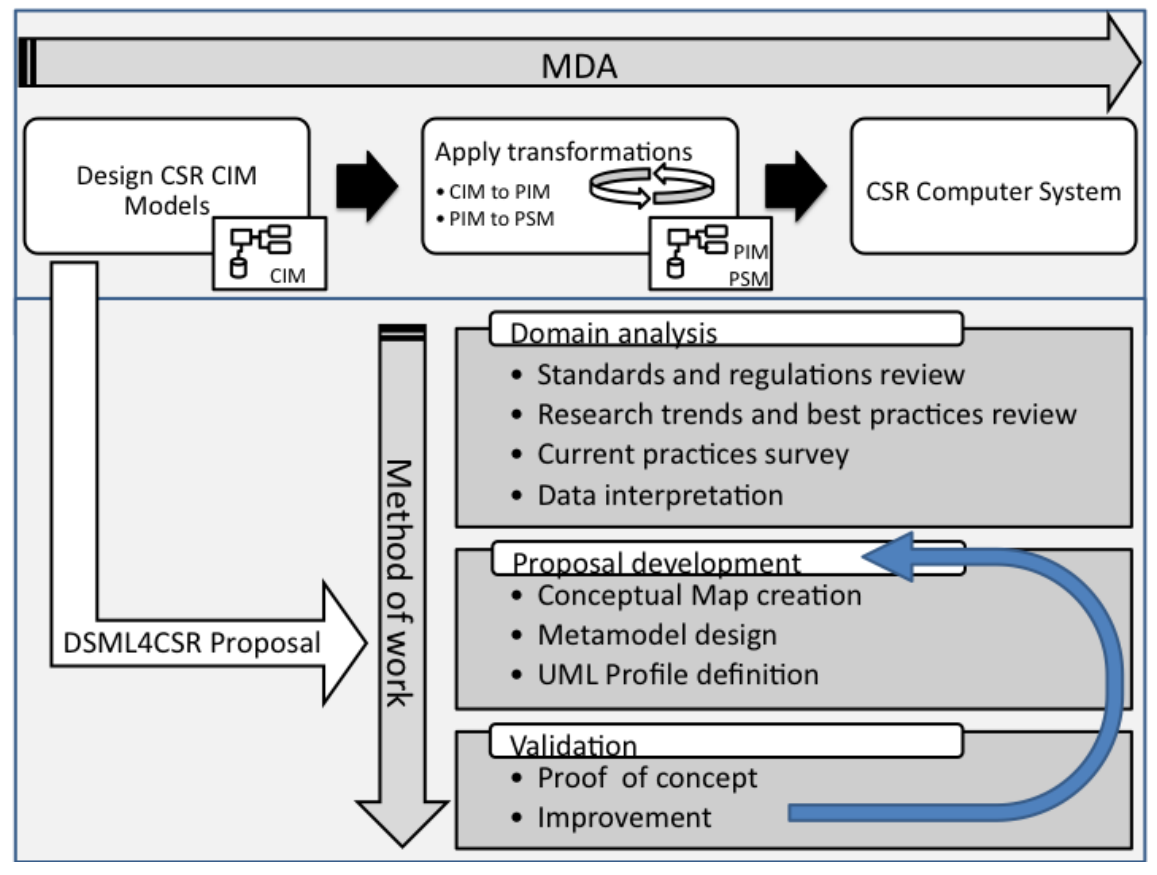

Figure 1: Method of work.

- Conceptual Map creation: definition of a CSR Conceptual Map to clarify the concepts and relationships identified in the data interpretation activity.

- Metamodel design: development and specification of the CSR Metamodel considering the artifacts and their relationships previously identified.

- UML Profile definition: implementation of the metamodel by a CSR UML profile that provides the DSML for CSR.

3. Validation

- Proof of concept: design of a CIM CSR Model applying the DSML4CSR to validate the proposal feasibility using a case study.

- Improvement: application of the modelling language to represent current practices in a case study provides feedback about the proposal's feasibility and allows to identify gaps and improvements. Dif- 
ferent iterations must be performed by reusing the results obtained from the application to enrich the CSR Metamodel as well as the CSR UML Profile. and results.

ISO 26000 [6] provides guidance on how businesses and organisations can operate in a socially responsible way. It provides guidance rather than requirements, therefore CSR cannot be certified unlike some other well-known ISO 275 which are the obtained results.

\section{Domain analysis}

\subsection{Corporate Social Responsibility standards and regulations review}

CSR was defined by [1] as the responsibility that enterprises have not only concept and there have been many definitions, there is consensus in considering that CSR intends to align the three P's (TBL-Triple Bottom Line) of a company: Profit, People and Planet 61.

Many international organisations have developed rules, recommendations and standards on CSR to guide its implementation. To identify the metamodel concepts we considered some of the most recognised and widely applied regulations: ISO 26000 [6], the Global Reporting Initiative (GRI) [7, 62] and the Global Compact [8]. In this section, we provide an overview of the main features, concepts and classification perspectives that each of these regulations define for the management, disclosure and improvement of CSR policies, actions standards, as for instance ISO 9000 for Quality Management 63. Instead, it

The following sections describe in detail how each step was implemented and helps clarify what social responsibility is, helps businesses and organisations translate principles into effective actions and shares best practices relating to social responsibility. ISO 26000 can be used to provide a way of how to proceed in a given situation or task [64. ISO 26000 defines CSR as the responsibility 

report must consider. These indicators are organised in three categories: Economic, Environmental and Social, which include the aspects that enterprises 
need to define and measure. Considering this proposal each company can define the specific concerns to include in its CSR report.

The United Nations Global Compact is a corporate sustainability initiative promoted by the United Nations. One of their results is the Guide to Corporate Sustainability [8] that defines ten principles for sustainability derived from the Universal Declaration of Human Rights, the International Labour Organizations Declaration on Fundamental Principles and Rights at Work, the Rio Declaration on Environment and Development, and the United Nations Convention Against Corruption. This guide enhances that companies must boost business processes and actions to establish a commitment with sustainability and the ten principles defined in the guide, as well as the annual report of results.

4.2. Research trends and best practices review

To improve the domain analysis we considered other research works performed regarding CSR management in order to find best practices and new trends that were worth to consider. These research works come mostly from the accounting and social area, where there is a very prolific research community 325 65.

After enumerating and classifying many research works regarding CSR management, in 66] the author proposes a set of Key Performance Indicators (KPI) to measure the impact of applying good CSR activities from a company perspective. One of the main goals of this work is to approach research and business points of view. The author identifies five benefits that companies can obtain from CSR policies: monetary brand value, customer attraction and retention, reputation, employer attractiveness, employee motivation and retention. The paper shows some examples of CSR performance indicators regarding each of these benefits in different case studies.

35 O'Connor 67] proposes a framework to organise CSR concepts as indicators and issues. This proposal is useful to review and improve concepts included in our metamodel because they define a full spectrum of concerns and candidate indicators in different contexts. 
The work described in 68] defines indicator and measurement systems for specific sectors. This approach is interesting because it shows how CSR is addressed differently depending on the sector, size, or country among other aspects also to be considered.

There are works like [9] that provide assessment on how to manage and control CSR, considering Management Control Systems (MCS) already implemented in companies. This work in particular analyses different companies in order to evaluate how they measure, perform and report CSR activities. The result of the analysis shows that many companies use their MCS to manage CSR, in an ad-hoc approach, including procedures to achieve their current CSR management needs. The development of specific computer systems to manage CSR using MDA will provide an agile integration of current management systems with new functionality.

In 69 the authors define a strategy to communicate CSR results, taking into account not only consumer views, but also company and CSR strategies. This proposal is useful regarding the final model implementation which must include the functionality and data necessary to provide stakeholders with accurate and reliable information.

Research is another important sector where CSR can be considered as a strategical issue. For instance, the European Commission Research and Innovation programme, Horizon 2020 [70] shows the strong commitment on the European Union, that has proposed a program that sets up the basis to include CSR as a strategic issue into the research community and projects. This program includes the Responsible Research and Innovation (RRI) section. This RRI promotes that all the stakeholders involved in research processes (researches, citizen, companies, organisations, etc.) align their goals and results with the values of society. In particular, RRI includes actions regarding open science to provide open access to research documents that describe the results; public engagement to promote participation from different sectors of the society; and also, educational, gender and ethical issues. 


\subsection{Current CSR practices survey} develop good policies on CSR, in order to analyse the CSR-related activities they are performing, which policies and methods they are using to disseminate results and if they use the standards and guidelines reviewed previously. All the companies evaluated have specific information about CSR or Sustainability in their corporate webs and the information used is freely available. We provided the classification according to the Global International Classification Standards from the MSCI 71 (see Table 1). We considered companies from different industrial sectors and also two nongovernmental organisations, so that we obtained a wider range of CSR management perspectives.

\begin{tabular}{|c|c|c|c|}
\hline Code & Name & Sector & Industry Group \\
\hline CS1 & Coca-Cola Company 72 & Consumer Staples & Food, Beverage and Tobacco \\
\hline $\mathrm{CS} 2$ & Inditex 73 & Consumer Discretionary & Retailing \\
\hline CS3 & Starbucks 74 & Consumer Discretionary & Consumer Services \\
\hline CS4 & McDonald's 75. & Consumer Discretionary & Consumer Services \\
\hline CS5 & Valencia Open 50076 & NGO & Local Public Service \\
\hline CS6 & Red Cross 77 & NGO & International Social Welfare \\
\hline
\end{tabular}

The actions and policies on CSR performed by these companies were compared with the principles, actions and performance indicators proposed by the main existing standards on CSR (see Table 2 and Table 3 ) with the aim of identifying a common set of elements to make up the metamodel to characterise CSR, and also other differential aspects that these companies could perform regarding CSR.

Table 2 points out the relationship between the main core subjects proposed by the ISO 26000 and the companies analysed. It shows the three main core categories identified as core subjects: economic, social and environmental. It also details the main issues of each core subjects and establishes the correspondences

In a similar way, Table 3 establishes the relationship between the GRI standard and the analysed companies. In this case, only the main subjects pro- 
posed by the standard are showed grouped in the three mentioned categories: economic, social and environmental.

395

\subsection{Data interpretation}

After analysing the standards, the research proposals, and the current practices performed by some representative companies, we concluded that CSR implementation means to adopt policies and standards in order to improve, modify or create new business processes, produce adequate information and provide execution of the processes.

In conclusion, aiming to define and organise the concepts and artifacts of the CSR Metamodel we identified the following issues:

- The Triple Bottom Line (Profit, People, and Planet), to organise the concepts because it is paramount to provide accurate aggregations considering the three P's.

- The concepts, terms, definitions, principles, practices and the core subjects proposed the ISO 26000 in its clause number 6.

- The UN Global Compact principles to identify areas where CSR can be considered: Human Rights, Labour, Environment and Anti-Corruption.

- The GRI recommendations and its categories, Economic, Environmental and Social, to organise how to disclose the information and what performance indicators are needed. Report guidelines, as well as report contents, must be considered in order to define which concepts must be included in the CSR Metamodel.

- Concepts like processes, actions indicators and measurements that appear in all the standards we reviewed.

- Aspects regarding who participates or those who are responsible for CSR processes: internal and external stakeholders, who are identified in all the reviewed proposals. 
Table 2: Comparison: subjects of ISO 26000 vs practices on CSR of analysed companies.

\begin{tabular}{|c|c|c|c|c|c|c|}
\hline & CS1 & CS2 & CS3 & $\mathrm{CS} 4$ & CS5 & CS6 \\
\hline \multicolumn{7}{|l|}{ Economic } \\
\hline \multicolumn{7}{|l|}{ Core subject: Fair operating practices } \\
\hline \multicolumn{7}{|l|}{ Issue 1: Anti-corruption } \\
\hline Issue 2: Responsible political involvement & & & $\mathrm{x}$ & & & \\
\hline \multicolumn{7}{|l|}{ Issue 3: Fair competition } \\
\hline Issue 4: Promoting social responsibility in the value chain & & & & $\mathrm{x}$ & & \\
\hline \multicolumn{7}{|l|}{ Issue 5: Respect for property rights } \\
\hline \multicolumn{7}{|l|}{ Social } \\
\hline \multicolumn{7}{|l|}{ Core subject: Human rights } \\
\hline Issue 1: Due diligence & & & & & & $\mathrm{x}$ \\
\hline Issue 2: Human rights risk situations & $\mathrm{x}$ & & & & & $\mathrm{x}$ \\
\hline Issue 3: Avoidance of complicity & & & & & & $\mathrm{x}$ \\
\hline Issue 4: Resolving grievances & & & & & & $\mathrm{x}$ \\
\hline Issue 5: Discrimination and vulnerable groups & & & $\mathrm{x}$ & & & $\mathrm{x}$ \\
\hline Issue 6: Civil and political rights & & & & & & $\mathrm{x}$ \\
\hline Issue 7: Economic, social and cultural rights & $\mathrm{x}$ & & $\mathrm{x}$ & & & $\mathrm{x}$ \\
\hline Issue 8: Fundamental principles and rights at work & & & & & & $\mathrm{x}$ \\
\hline \multicolumn{7}{|l|}{ Core subject: Labour practices } \\
\hline Issue 1: Employment and employment relationships & $\mathrm{x}$ & & $\mathrm{x}$ & & $\mathrm{x}$ & \\
\hline Issue 2: Conditions of work and social protection & $\mathrm{x}$ & & $\mathrm{x}$ & & $\mathrm{x}$ & \\
\hline Issue 3: Social dialogue & $\mathrm{x}$ & & & & $\mathrm{x}$ & \\
\hline Issue 4: Health and safety at work & & & $\mathrm{x}$ & & $\mathrm{x}$ & $\mathrm{x}$ \\
\hline Issue 5: Human development and training in the workplace & $\mathrm{x}$ & & $\mathrm{x}$ & & $\mathrm{x}$ & $\mathrm{x}$ \\
\hline \multicolumn{7}{|l|}{ Core subject: Community involvement and development } \\
\hline Issue 1: Community involvement & $\mathrm{x}$ & & $\mathrm{X}$ & & $\mathrm{x}$ & $\mathrm{x}$ \\
\hline Issue 2: Education and culture & $\mathrm{x}$ & & & & $\mathrm{x}$ & $\mathrm{x}$ \\
\hline Issue 3: Employment creation and skills development & $\mathrm{x}$ & & & & $\mathrm{x}$ & \\
\hline \multicolumn{7}{|l|}{ Issue 4: Technology development and access } \\
\hline Issue 5: Wealth and income creation & & & & & $\mathrm{x}$ & \\
\hline Issue 6: Health & & & & & & $\mathrm{x}$ \\
\hline Issue 7: Social investment & $\mathrm{x}$ & & $\mathrm{X}$ & & $\mathrm{x}$ & $\mathrm{X}$ \\
\hline \multicolumn{7}{|l|}{ Core subject: Consumer issues } \\
\hline \multicolumn{7}{|l|}{$\begin{array}{l}\text { Issue 1: Fair marketing, factual and unbiased information and fair contrac- } \\
\text { tual practices }\end{array}$} \\
\hline Issue 2: Protecting consumers' health and safety & & & & $\mathrm{x}$ & & \\
\hline Issue 3: Sustainable consumption & & & & $\mathrm{x}$ & & \\
\hline Issue 4: Consumer service, support, and complaint and dispute resolution & & & & $\mathrm{x}$ & & \\
\hline \multicolumn{7}{|l|}{ Issue 5: Consumer data protection and privacy } \\
\hline \multicolumn{7}{|l|}{ Issue 6: Access to essential services } \\
\hline Issue 7: Education and awareness & & & & $\mathrm{X}$ & & \\
\hline \multicolumn{7}{|l|}{ Environmental } \\
\hline \multicolumn{7}{|l|}{ Core subject: The environment } \\
\hline Issue 1: Prevention of pollution & & $\mathrm{x}$ & $\mathrm{x}$ & $\mathrm{x}$ & & \\
\hline Issue 2: Sustainable resource use & & $\mathrm{x}$ & $\mathrm{x}$ & $\mathrm{x}$ & & \\
\hline Issue 3: Climate change mitigation and adaptation & & $\mathrm{x}$ & $\mathrm{x}$ & $\mathrm{x}$ & & \\
\hline $\begin{array}{l}\text { Issue 4: Protection of the environment, biodiversity and restoration of nat- } \\
\text { ural habitats }\end{array}$ & & $\mathrm{x}$ & $\mathrm{x}$ & $\mathrm{x}$ & & \\
\hline
\end{tabular}


Table 3: Comparison: subjects of GRI vs practices on CSR of analysed companies.

\begin{tabular}{|c|c|c|c|c|c|c|}
\hline & CS1 & $\mathrm{CS} 2$ & CS3 & CS4 & CS5 & CS6 \\
\hline \multicolumn{7}{|c|}{ Economic } \\
\hline \multicolumn{7}{|l|}{ Economic performance } \\
\hline \multicolumn{7}{|l|}{ Market presence } \\
\hline Indirect economic impact & & & $\mathrm{X}$ & & & \\
\hline \multicolumn{7}{|l|}{ Procurement practices } \\
\hline \multicolumn{7}{|c|}{ Environmental } \\
\hline Materials & & $\mathrm{X}$ & $\mathrm{x}$ & $\mathrm{x}$ & & \\
\hline Energy & & $\mathrm{X}$ & $\mathrm{X}$ & $\mathrm{X}$ & & \\
\hline Water & & & $\mathrm{X}$ & $\mathrm{x}$ & & \\
\hline Biodiversity & & & & $\mathrm{x}$ & & \\
\hline Emissions & & $\mathrm{x}$ & & $\mathrm{x}$ & & \\
\hline Effluents and Waste & & & & $\mathrm{x}$ & & \\
\hline Products and Services & & & $\mathrm{X}$ & $\mathrm{X}$ & & \\
\hline Compliance & & $\mathrm{X}$ & $\mathrm{X}$ & $\mathrm{x}$ & & \\
\hline Overall & & $\mathrm{X}$ & & $\mathrm{X}$ & & \\
\hline Supplier Environmental Assessments & & & & $\mathrm{x}$ & & \\
\hline \multicolumn{7}{|c|}{ Social } \\
\hline Labour practices and Decent Work & $\mathrm{x}$ & & $\mathrm{x}$ & & $\mathrm{X}$ & $\mathrm{X}$ \\
\hline Human Rights & $\mathrm{x}$ & & & & $\mathrm{X}$ & $\mathrm{X}$ \\
\hline Society & $\mathrm{X}$ & & $\mathrm{X}$ & $\mathrm{X}$ & $\mathrm{X}$ & $\mathrm{X}$ \\
\hline Product Responsibility & & & & $\mathrm{X}$ & & \\
\hline
\end{tabular}

The main conclusions regarding the comparison of current practises were three: (1) CSR is a wide concept and each enterprise needs to identify their objectives and specific actions according to its strategy and features, hence the need to define a methodology to guide enterprises in its implementation [78; (2) even though there are differences among enterprises that belong to different industrial sectors, it is possible to define a common set of actions and results that conforms a basic set of concepts to define a first version of a CSR Metamodel; and (3) there is a concordance between the issues proposed by the main standards and regulations like ISO 26000 or GRI, and actual practices

${ }_{430}$ performed by enterprises. Therefore this domain analysis is a good starting point to define the requirements for the mentioned metamodel. 


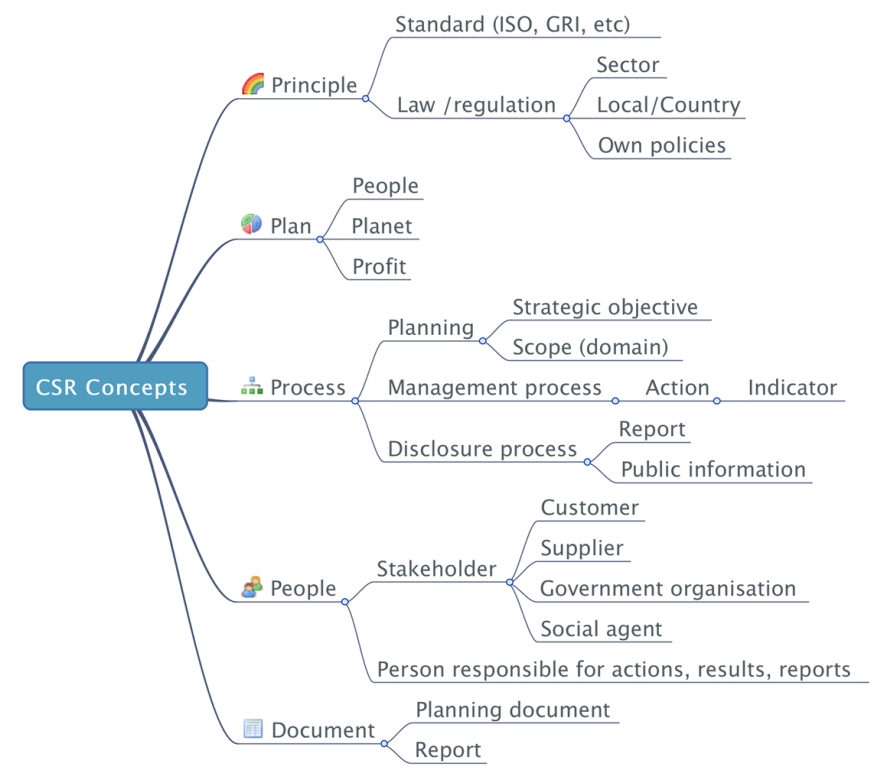

Figure 2: CSR Conceptual Map obtained from data interpretation.

\section{Proposal development}

\subsection{CSR Conceptual Map creation}

In order to facilitate the interpretation of the domain analysis and the elicitation activity, we developed a CSR Conceptual Map (see Figure 22) to clarify the main concepts that should be included in the metamodel.

This Conceptual Map shows all the concepts identified in the previous section Data interpretation. To classify these concepts we have answered the questions why we want to perform CSR strategies, what and how we want to perform CSR activities, who participates in these actions and which results we want to obtain.

- Principle (Why) identifies and represents regulations, standards and policies (including company's own initiatives) that the company wants, or needs to adopt in its CSR policy proposal. This core concept represents issues and policies that companies need to select in order to identify what 
they want to improve regarding CSR objectives and strategy. The accepted standards, regulations, local laws, and the own policies provide the specific classification of the principles.

- Plan (What) defines what the company is going to do in order to accomplish strategic CSR objectives. There can be plans focused on each of the three P's People, Profit and Planet.

- Process (How) considers all the activities that the company defines in order to perform plans on CSR. This concept includes three types of processes: planning, identified to establish the scope, strategic objectives and schedule to implement CSR projects; management, to classify processes that control the execution of the actions included in the planning processes; and disclosure, that are the processes needed to report and provide information about the actions and their results.

- People (Who) represents both the stakeholders involved, and those who are responsible for the results and management of the actions included in the processes.

- Document (Result) means all the reports and information generated in any type of support, either to disseminate the information or to present results for official bodies. First, this concept includes the plan as the document that brings together everything the company wishes to do in CSR. And second, it shows the concept report that considers all the disclosure results that the company must provide according to standards and regulations adopted and laws that must be enforced.

\subsection{CSR Metamodel design}

The CSR Metamodel is defined from the concepts identified in the domain analysis, taking into account the criteria explained in the previous sections and the resulting CSR Conceptual Map. It is organised into two packages (see Figure 3) in order to separate the elements needed for modelling (CoreElements) from those related directly with the CSR domain (CSRElements): 


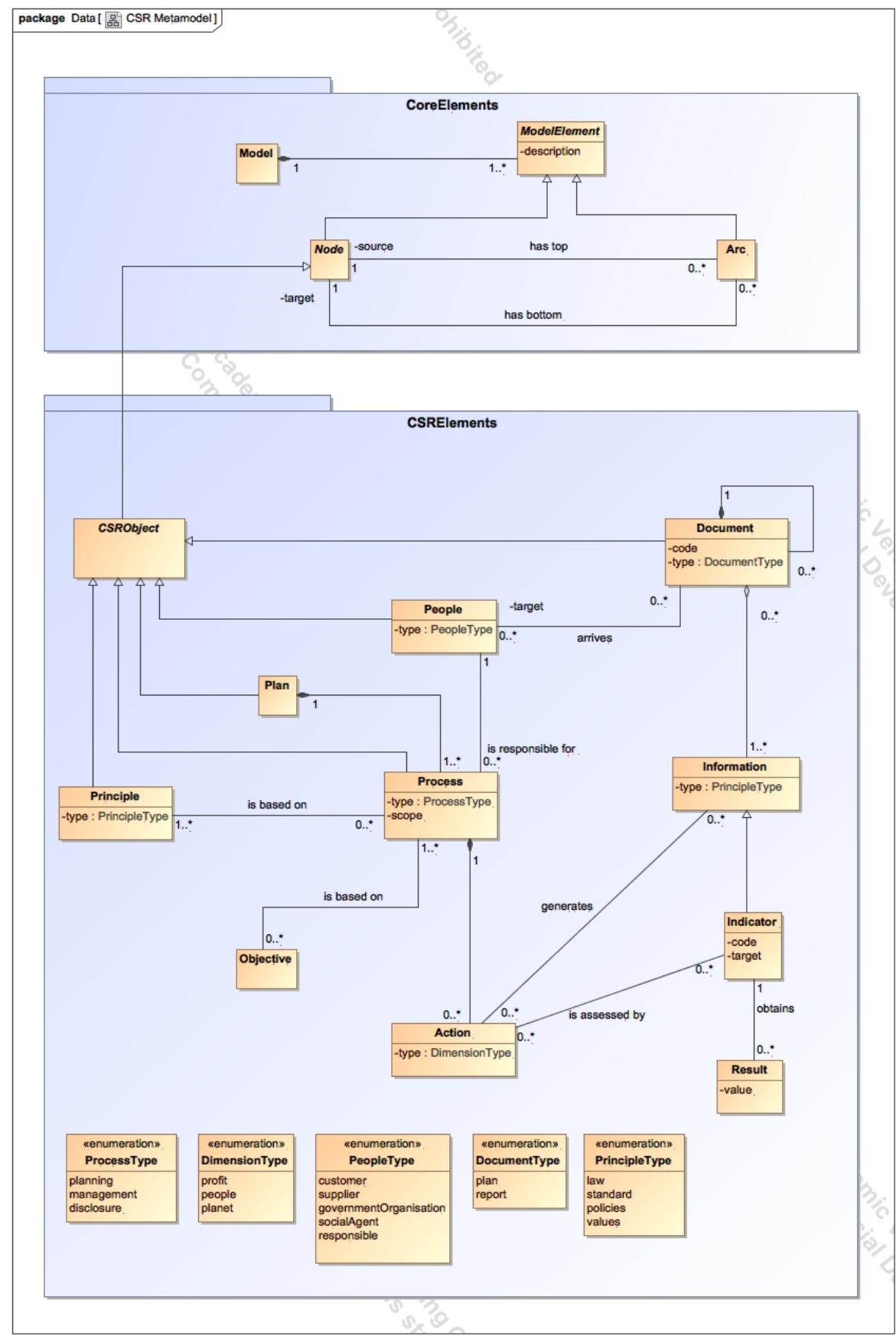

Figure 3: CSR Metamodel. 
1. CoreElements: this package includes the generic elements used to develop CSR diagrams.

- Model: this class represents groups of CSR diagrams that can be designed to model CSR issues.

- ModelElement: it is an abstract class that represents the generic concepts that enterprises need to manage, taking into account their CSR strategy. A Model is composed by at least one or by many ModelElements.

- Node: it represents a subset of ModelElements that are useful to represent anything, any fact or any concept needed to manage CSR.

- Arc: this class represents the specific ModelElements which are used to connect nodes.

2. CSRElements: this package includes the specific CSR objects defined to represent CSR diagrams.

- CSRObject: it represents a subset of the class Node that can be used to represent common concepts managed in enterprises regarding their CSR strategy.

- Principle: this class is a type of CSRObject that represents a set of CSR management initiatives based on CSR standards, laws ans regulations. An instance of Principle is implemented by many processes.

- Plan: this class is a type of CSRObject, an instance of this class explains what processes (when, how, and by whom) need to be performed to accomplish the strategic objectives regarding the CSR principles.

- Process: this class is a type of CSRObject, an object of this class represents a sequence of interdependent organised activities defined to support CSR. A process can be classified as planning, management or disclosure. An instance of Process:

- is implemented based on one or many principles, 
- is part of one plan,

- is composed by one or many actions,

- is defined to accomplish one or more objectives,

- is one person's (an instance of people) responsibility.

- People: this class is a type of CSRObject that represents the set of roles involved in CSR management. An instance of People can be a stakeholder reported with none or many documents and can be responsible for none or many processes.

- Document: this class is a type of CSRObject. Each object of this class represents a group of structured and organised in an specific template data. A Document can be composed by many other documents or none, it can be provided to many people, it is obtained from one process execution, and it shows Information's instances.

- Objective: this class represents the goals that a company defines in order to develop its CSR processes. Many processes can be defined based on an objective.

- Action: this class represents the set of tasks that a company defines in order to perform its CSR processes. Each action is included in a process. An action is assessed defining many indicators.

- Information: an object of this class represents data generated by actions execution, or provided by other external sources. An instance of Information can be in the composition of many documents or none, can be generated by many actions execution or none (external sources).

- Indicator: this class represents the measurable variables defined to assess the actions performance. An indicator can evaluate many actions and can provide many results. This class is a type of Information.

- Result: this class represents the set of values obtained from the indicators measurement. A result is obtained only from an indicator. 
- ProcessType: this enumeration specifies the process classification proposed regarding CSR project needs.

- DimensionType: this enumeration specifies the types of CSR actions, regarding the Triple Bottom Line.

- PeopleType: this enumeration specifies the types of participants identified, such as the person responsible for the processes and other external actors that can use information from CSR actions.

- DocumentType: this enumeration specifies the types of CSR Documents to support CSR management and disclosure.

- PrincipleType: this enumeration classifies the initiatives that can be mandatory, such as laws, recommendations, standards, or company internal policies.

The enumerations are defined considering the concepts elicited from the standards and guides analysed. Although there are seven ISO 26000 core concepts, we only considered three issues in the DimensionType following the TBL, because all these ISO 26000 core concepts can be re-organised in these three. For example, Organizational Governance, Human Rights, and Labor Practices could be included in the dimension People; The Environment would correspond to Planet; and Fair Operation Practices, Consumer Issues, and Community Involvement and Development to Profit. In the case, that an enterprise wishes to define a wider range of concepts, these can be added to the corresponding enumeration.

\subsection{CSR UML Profile definition}

We extended the capabilities of UML defining a UML profile that defines the Domain-Specific Modelling Language for CSR (DSML4CSR) in order to provide an implementation of the CSR Metamodel. Figure 4 shows the diagram of this profile performed with MagicDraw [79, which is called 'CSR UML Profile'. Each CSR Metamodel element extends a UML constructor in order to create the 'CSR UML Profile': 


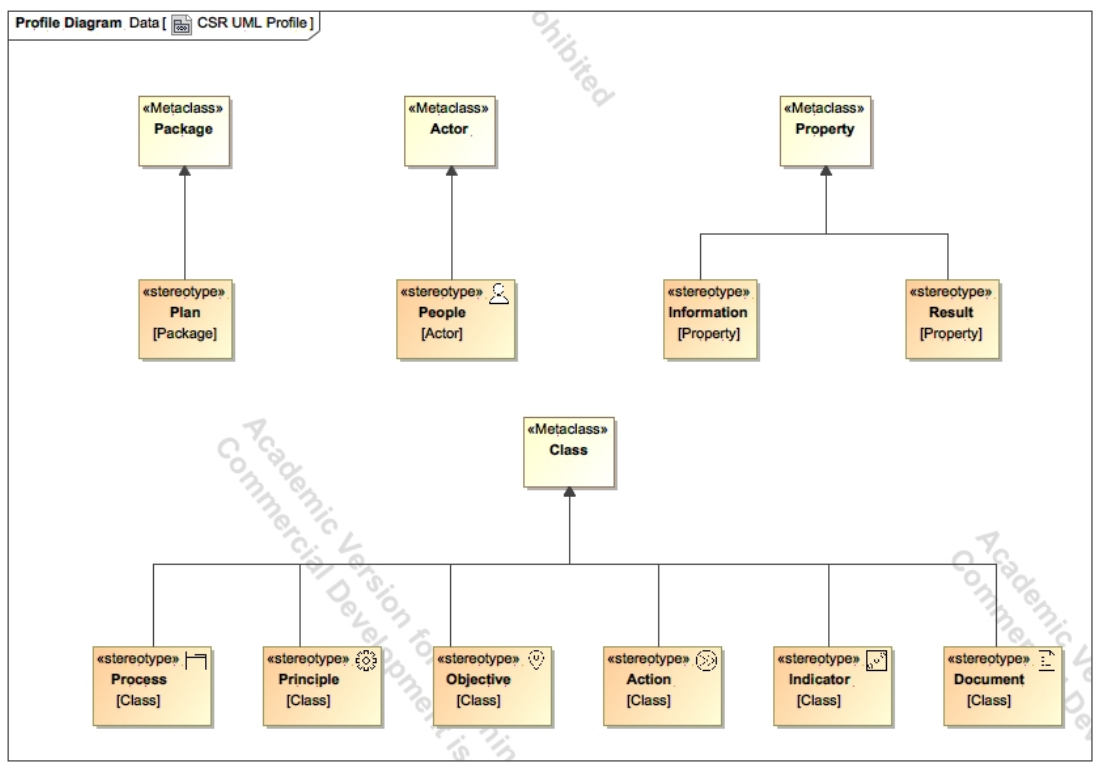

Figure 4: CSR UML Profile.

- Plan extends Package. Plan is used to aggregate all the CSR issues that a company defines regarding a strategic project or topic, such as processes, actions and results. The use of Package allows to establish the framework where all the other concepts are included.

- People extends the metaclass Actor, since stakeholder or responsible person are similar concepts to those represented by an actor in UML.

- The concepts Process, Principle, Objective, Action, Indicator, and Document extend the metaclass Class. They can be used as basic elements of the CSR diagrams representing sets of objects that have different attributes.

- Information and Result extend Property, taking into account that they are characteristics of the class Document and Indicator. is a CSR Model. The CSR Model obtained by means of this language makes 
possible to get several CSR Diagrams of an enterprise. For example, Figure 5 shows the CSR Model of Pamesa Cerámical for the Environmental Action Plan. However this model could included more CSR Diagrams to represent other enterprise plans. Once, the CSR Model of an enterprise is completed we could consider that it defines the CSR Map of this enterprise. Therefore, the CSR Map of an enterprise, as a site map represents the structure of a web, would show the main processes, people, indicators, etc. of this enterprise related to CSR.

Table 4 shows the stereotypes created for the 'CSR UML Profile' using the icons from Flaticom 80]. Finally, this profile is implemented using EMF and GMF of Eclipse 81 to obtain a tool that supports the development of CSR Models using the DSML4CSR. This graphical representation close to real enterprise concepts provides better understanding to all the CSR stakeholders.

\footnotetext{
${ }^{1}$ Case Study presented in Section 6
} 


\begin{tabular}{|c|c|c|}
\hline Stereotype & Elements to model & Icon \\
\hline$<<$ Plan $>>$ & $\begin{array}{l}\text { A set of processes related to CSR issues jointly with } \\
\text { the performed actions, involved people, generated doc- } \\
\text { umentation, etc. }\end{array}$ & $<<$ Plan $>>$ \\
\hline$<<$ Document $>>$ & $\begin{array}{l}\text { Collection of different types of data, as for example a } \\
\text { planning document or a report }\end{array}$ & \\
\hline$<<$ Actor $>>$ & $\begin{array}{l}\text { Any person who participates or is responsible for a } \\
\text { CSR process }\end{array}$ & \\
\hline$<<$ Process $>>$ & $\begin{array}{l}\text { Any set of organised actions defined to plan, manage } \\
\text { or disclose RSC }\end{array}$ & \\
\hline$<<$ Principle $>>$ & $\begin{array}{l}\text { Any standard, law or regulation chosen to develop } \\
\text { CSR actions }\end{array}$ & \\
\hline
\end{tabular}

$<<$ Objective $>>\quad$ Any goal defined to be accomplished

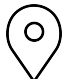

\begin{tabular}{lll}
\hline$<<$ Action $>>$ & Any activity defined to achieve the strategic objectives \\
\hline$<$ Indicator $>>$ & $\begin{array}{l}\text { Criteria used to measure the accomplishment of CSR } \\
\text { actions }\end{array}$ & \\
\hline & & \\
\hline$<<$ Information $>>$ & Any kind of data that can be showed in a document & $<<$ Information $>>$ \\
\hline$<<$ Result $>>$ & Value obtained from one indicator measurement & $<<$ Result $>>$ \\
\hline
\end{tabular}

Table 4: Stereotypes and icons that can be used within the 'CSR Model'. 


\subsection{Proof of concept}

Taking into account that a case study can be a single case to evaluate a research theory in order to obtain results that can generalise or improve this theory [82, we considered Pamesa Cerámica [83] as our case study.

This company designs, manufactures and trades ceramic products, and it already develops some policies in sustainability. The company develops actions regarding CSR that can be included into ISO 26000 core subjects: Labor Practices, The Environment and Community Involvement and Development.

We reviewed Pamesa's CSR initiatives in previous tasks included into the research project carried out to develop a Model-Driven CSR Framework [20]. This project provides among others, two main results:

1. An Agile Model-Driven Methodology for CSR (AMDM4CSR) [78 to guide the implementation of CSR Computer Systems which is structured in the following processes:

605

- Strategic Planning (P1): to analyse the CSR strategic objectives to define the company's CSR Action Plan.

- CSR Modelling (P2): where modelling languages are used to represent CSR models at CIM level.

- MDA Application (P3): the CSR model at CIM level is transformed into a PIM model, and then into a PSM model with the final aim of generating the CSR Computer System.

- Assessment (P4): to evaluate and improve the result of the methodology and also the process.

2. A Domain-Specific Modelling Language for CSR (DSML4CSR) implemented as a 'CSR UML Profile' based on the CSR Metamodel which are described in the current paper. 
We applied the methodology processes in earlier stages of the project to the particular CSR Pamesa's initiatives and we validated and improved some aspects of its CSR management. In more detail, as the result of the first process of the methodology, Strategic Planning (P1), we completed a Pamesa's CSR Action Plan [78] that is partially included in this paper (see Table 55). Regarding the execution of the second process of the methodology, CSR Modelling (P2), we developed a first version of the CSR Model using UML. But this model was rather simple and all the concepts were represented by classes with no differential characteristic. As a result, we considered defining a DSML4CSR to develop models that show specific CSR aspects and that make it easier to design CSR Models at CIM level.

In order to validate if this DSML4CSR is useful we considered two conditions as evaluation criteria:

- The proposed DSML4CSR allows to represent the company CSR management concepts and issues as UML artifacts.

- The obtained CSR CIM model can be used to represent, analyse and improve the company CSR business processes and policies.

Taking into account the fulfilling of the project processes, their results and the DSML4CSR proposed in this paper, we developed a second version of the Pamesa's CSR Model using the DSML4CSR (see Figure 5).

Pamesa's CSR Action Plan (see Table 5 includes: strategic objectives, actions, responsible persons and indicators. The CSR diagram obtained represents these concepts and their relationships, not only using graphic icons closer to the real world, but also providing specific characteristics that support a better understanding of what current CSR Pamesa's policies are.

Thus, the company can have a general vision of what are the concrete elements (strategic objectives, actions, indicators, responsible person, etc.) that are included in this specific CSR Action Plan. Stakeholders can easily view which are their concerns regarding the action plan, what relationships are established among the concepts, where can problems be and they can identify 
Table 5: Pamesa's CSR Environmental Action Plan for strategic objectives: SO1 (Reducing waste production both in quantity and hazard level) and SO2 (Reduce deforestation).

\begin{tabular}{|c|c|c|c|}
\hline SO & Action & Responsible person & Indicator \\
\hline \multirow[t]{3}{*}{ SO1 } & $\begin{array}{l}\text { (A1.1) Use of cogenera- } \\
\text { tion turbines to produce } \\
\text { electricity and to reuse } \\
\text { gas }\end{array}$ & $\begin{array}{l}\text { Quality Assurance Man- } \\
\text { ager and Production } \\
\text { Manager }\end{array}$ & $\begin{array}{l}\text { (I1.1.1) } \mathrm{CO}^{2} \text { emissions } / \mathrm{m}^{2} \text { pro- } \\
\text { duction }\end{array}$ \\
\hline & & & Combustible \\
\hline & & & consumption $/ \mathrm{m}^{2}$ production \\
\hline \multirow[t]{4}{*}{$\mathrm{SO} 2$} & $\begin{array}{l}\text { (A2.1) Use of euro pal- } \\
\text { lets }\end{array}$ & $\begin{array}{l}\text { Quality Assurance Man- } \\
\text { ager and Production } \\
\text { Manager }\end{array}$ & $\begin{array}{l}\text { (I2.1.1) Number of euro pallets } \\
\text { distributed monthly }\end{array}$ \\
\hline & $\begin{array}{l}\text { (A2.2) Recycle card- } \\
\text { board, paper, plastic } \\
\text { and other materials }\end{array}$ & $\begin{array}{l}\text { Quality Assurance Man- } \\
\text { ager }\end{array}$ & $\begin{array}{l}\text { (I2.2.1) Cardboard containers re- } \\
\text { cycled }\end{array}$ \\
\hline & & & $\begin{array}{l}\text { (I2.2.2) Plastic containers recy- } \\
\text { cled }\end{array}$ \\
\hline & & & $\begin{array}{l}\text { (I2.2.3) Containers other materi- } \\
\text { als recycled }\end{array}$ \\
\hline
\end{tabular}

what improvements can be proposed.

Finally, applying to this CSR Model at CIM level successive transformations following MDA, a CSR Computer System could be implemented. plan. Nevertheless, after trying to represent a CSR diagram regarding Pamesa's 


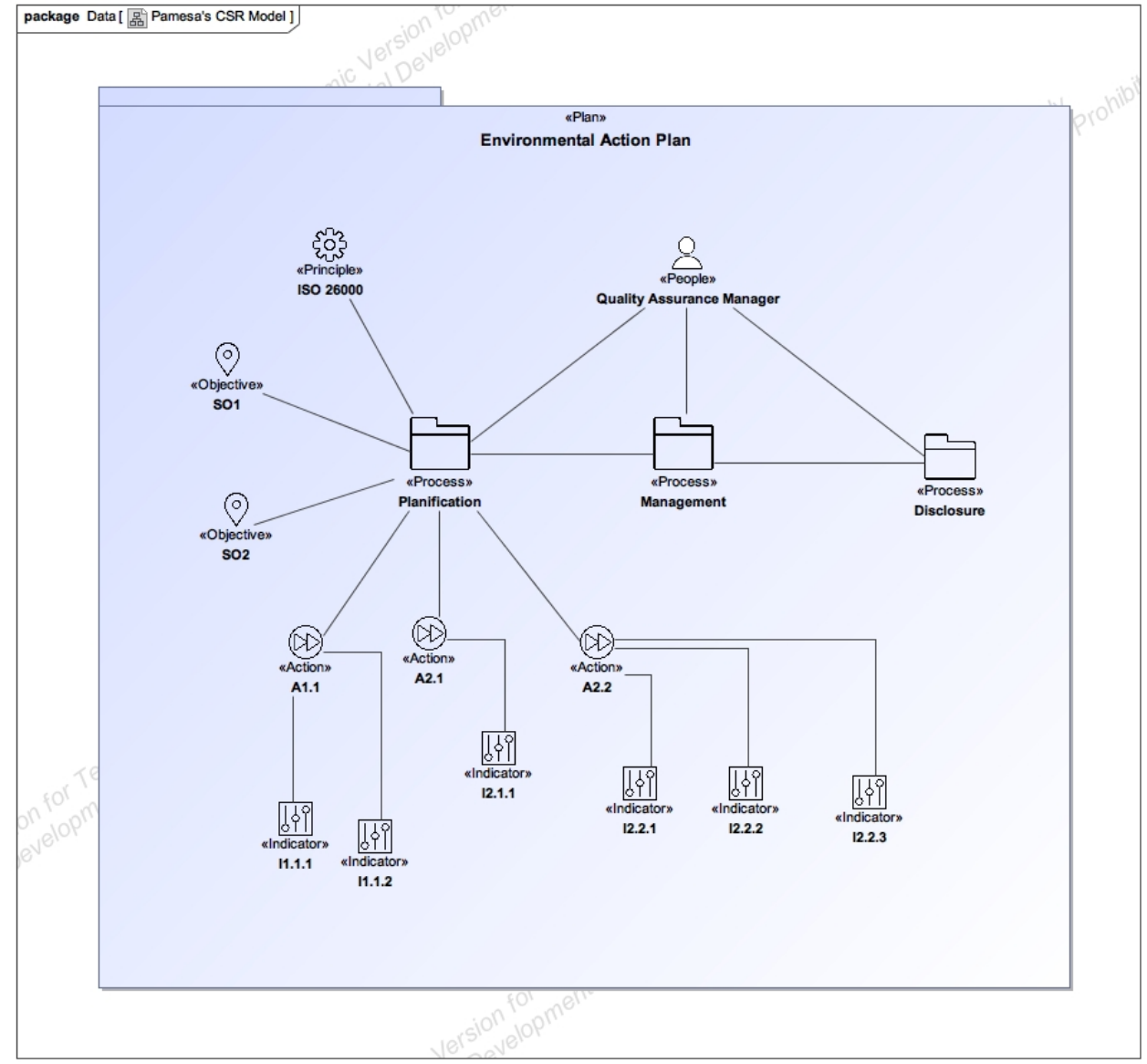

Figure 5: CSR Model of Pamesa Cerámica for Environmental Action Plan. 
CSR Action Plan, we noticed that some main aspects were missing, and we considered that Plan should be represented as an independent concept that leads the company's strategy and links all the other artifacts.

Finally, it is worth detailing some learned lessons obtained from this case study:

- These models are a good starting point to characterise and improve CSR processes.

- The development of models as case studies following this DSML4CSR can be a sound facility to provide best practices on CSR to many companies that need support to implement CSR policies.

- The use of the DSML4CSR contributes to review if a company already performs CSR policies according to international standards and regulations, which can be mandatory in a short term.

- Designing CIM models is the first step to apply the Model-Driven Engineering paradigm to the development of CSR Computer Systems.

\section{Conclusion}

\subsection{Obtained results}

CSR is extensively discussed in the literature and it is supported by many standards and regulations, but it is still an abstract issue and companies apply heterogeneous processes and different internal policies to implement its management.

There are well accepted regulations and recommendations on CSR that can guide enterprises in the management and communication of their policies, plans and results in this subject. However, companies find it difficult to manage the information, plans and policies needed as well as to disseminate their results in CSR. Enterprises need not only a guide to implement CSR plans and policies, but also a computer system aligned with other information systems that addresses the CSR processes, data and information dissemination. 
CSR must be considered from the technological, human and organisational point of view in order to develop computer systems that take into account specific CSR processes and reporting of information. In this sense, one of the benefits of the CSR Metamodel is that it proposes a non-abstract set of elements to represent how CSR can efficiently be managed. Moreover, we observed during the development of the research project that people responsible for managing CSR are usually not engineers and have few modelling skills. Therefore we need to provide them a tool easy to use and a friendly design environment.

To achieve this goal, we chose a UML Profile to implement the modelling tool and we defined icons closer to real objects for representing the artifacts. Adopting this solution, first, we did not need to develop the whole metamodel, but only the package corresponding to the specific elements related to CSR. And second, we can use a representation closer to people responsible of CSR management that will feel more comfortable representing CSR Models.

The CSR Metamodel and the 'UML Profile for CSR' presented in this paper are the result of various iterations performed in the tasks of the aforementioned project focused on developing a CSR Framework. In particular, the CSR Metamodel has been obtained after several revisions: beginning with the first version obtained from the domain analysis until the last one, which includes improvements and gradual changes.

The DSML4CSR can be used as an Enterprise Modelling Language to obtain enterprise models focused on the CSR dimension. The models subsequently obtained could be used, among many other applications:

- To make the knowledge about CSR explicit both inside and outside the enterprise. This issue is very important especially in CSR domain since social dimension and communication are actual needs implicit in good CSR practices.

- To improve CSR knowledge and management. This modelling language benefits CSR process management since the CSR models make visible the AS-IS situation and facilitate the analysis of which should be the TO-BE 
scenario.

- To apply MDA on specific CSR models with the aim of obtaining more maintainable CSR Computer Systems that allows to record, validate, consult, evaluate and analyse results on CSR.

725

\subsection{Limitations of the work and future research}

We can declare that the proposed CSR Metamodel meets many of the needs a company has to manage CSR, although we will develop new case studies to improve aspects regarding other domains. Moreover, more experiences related to the transformation from CIM to PIM are needed in order to improve the quality of CSR Computer Systems.

The model can have some limitations as well as many other models. Business people used to be reluctant to this kind of models. If we propose and use models easy to understand, close to their concerns they will realise that the gap between research and real-word is getting smaller.

The work described in this paper stops at the creation of the computer model, but we proposed this approach because it is useful when requirements can change and the users include new needs. The MDA approach and the use of CIM Models have the advantage that issues related to CSR are modelled at conceptual level and quickly technology changes do not affect these models.

Our future research work is focused on the use of the DSML4CSR in some other representative case studies to improve and provide new versions of the CSR Metamodel and the 'CSR UML Profile'. These results will also complete the Agile Model-Driven Methodology and the whole project we develop to define a Model-Driven CSR Framework. Moreover, the method and the obtained results could be adapted to be applied to other domains, in particular to healthcare. Beyond existing HL7 efforts, similar work could be done in the field of development of software based on clinical practice guidelines (CPG), in which models developed using Domain-Specific Modelling Languages are used.

Regarding the method of work included in this paper we will review the steps and include a Action Design Research Approach 84. This approach 
takes into account that the IT artifacts can emerge from the interaction with organisational context. This situation can provide new and good inputs to the metamodel and the proposed DSML4CSR. Actually we think that the stages that this methodology sets up can improve some of the steps and the results of the methodology we used.

The company feedback was also important to improve the proposal. We consider that it is necessary to review new assets, policies and approaches that should require new artifacts in the metamodel design. Furthermore, as new technology products arise in the management of strategic activities, the managers involved realise that they can obtain more information to improve their decisions and results and identify new requirements. Therefore, these models and the computer systems must continuously evolve. This is one of the reasons that justifies the use of MDA.

\section{Acknowledgements}

This work has been partly funded by the Project 'Definition of a Metamodel and Application of MDA to the Generation of Software to Support Corporate Social Responsibility' and partly supported by the Spanish Ministry of Economy and Competitiveness and the EU FEDER programme through grant TIN201453749-C2-1-R. We would also like to thank the company Pamesa for enabling us to use their public data about CSR.

\section{References}

[1] A. B. Carroll, Corporate Social Responsibility: Evolution of a Definitional Construct, Business \& Society 38 (3) (1999) 268-295.

[2] A. B. Carroll, K. M. Shabana, The Business Case for Corporate Social Responsibility: A Review of Concepts, Research and Practice, International Journal of Management Reviews 12 (1) (2010) 85-105. doi:10.1111/j. $1468-2370.2009 .00275 . x$. 
[3] Corporate Social Responsibility (CSR), http://ec.europa.eu/growth/ industry/corporate-social-responsibility/, [Accessed 20 October 2017].

[4] S. Putrevu, J. McGuire, D.-S. Siegel, D.-M. Smith, Corporate social responsibility, irresponsibility, and corruption: Introduction to the special section, Journal of Business Research 65 (11) (2012) 1618-1621. doi:http: //dx.doi.org/10.1016/j.jbusres.2011.10.020

[5] F. Székely, M. Knirsch, Responsible Leadership and Corporate Social Responsibility: Metrics for Sustainable Performance, European Management Journal 23 (6) (2005) 628-647.

[6] ISO 26000, Guidance on social responsibility, Tech. rep., ISO, [Accessed 20 October 2017] (2010).

[7] G4 SUStainABILITY REPORTING GUIDELINES, Tech. rep., Global Reporting Initiative, [Accessed 20 October 2017] (2015).

[8] Guide to Corporate Sustainability, Tech. rep., United Nations Global Compact, [Accessed 20 October 2017] (2015).

[9] D.-L. Arjaliès, J. Mundy, The use of management control systems to manage CSR strategy: A levers of control perspective, Management Account-

प ing Research 24 (4) (2013) 284-300. doi:http://dx.doi.org/10.1016/ j.mar.2013.06.003.

[10] P. Habek, R.Wolniak, Relationship between Management Practices and Quality of CSR Reports, Procedia - Social and Behavioral Sciences 220 (2016) 115-123. doi:http://dx.doi.org/10.1016/j.sbspro.2016.05. 475 .

[11] K. Hinkelmann, et al., A new paradigm for the continuous alignment of business and IT: Combining enterprise architecture modelling and en-

प terprise ontology, Computers in Industry 79 (2016) 77-86. doi:http: //dx.doi.org/10.1016/j.compind.2015.07.009 
[12] MDA Guide Version 1.0.1, Tech. rep., Object Management Group, [Accessed 20 October 2017] (June 2003).

[13] P. Klint, R. Lämmel, C. Verhoef, Toward an engineering discipline for grammarware, ACM Transactions on Software Engineering Methodology 14 (3) (2005) 331-380. doi:http://doi.acm.org/10.1145/1073000

[14] J.-M. Favre, Towards a Basic Theory to Model Model Driven Engineering, in: In Workshop on Software Model Engineering, WISME 2004, joint event with UML 2004 International Workshop on Software Model Engineering, 2004.

[15] R. France, B. Rumpe, Model-driven Development of Complex Software: A Research Roadmap, in: In 2007 Future of Software Engineering, FOSE'07, IEEE Computer Society, 2007, pp. 37-54.

[16] R. H. Weston, Business benefits from enterprise modelling and integration, in: IEE Colloquium on Next Generation I.T. in Manufacturing (Digest No: 1997/315), 1997, pp. 2/1-2/3. doi:10.1049/ic:19971042.

[17] G. Doumeingts, D. Chen, Interoperability Development for Enterprise Applications and Software, in: P. Cunningham, M. Cunningham, P. Fatelnig (Eds.), In Building the Knowledge Economy: Issues, Applications, Case Studies, eBusiness, IOS Press Amsterdam, 2003.

[18] F. Vernadat, Enterprise Modelling and Integration: Principles and Application, Chapman and Hall, 1996.

[19] G. Berio, A. Opdahl, V. Anaya, M. Dassisti, Deliverable DEM 1: UEML 2.1, Tech. rep., INTEROP (2005).

[20] C. Campos, R. Grangel, How to Apply Model Driven Engineering to Develop Corporate Social Responsibility Computer Systems, in: M. A. Fernández-Izquierdo, M. J. Muñoz-Torres, R. León (Eds.), Modeling and 
Simulation in Engineering, Economics, and Management, Vol. 145 of Lecture Notes in Business Information Processing, Springer Berlin Heidelberg, 2013, pp. 42-50. doi:10.1007/978-3-642-38279-6_5.

[28] Object Management Group (OMG), https://www.omg.org/, [Accessed 20 October 2017].

[29] Microsoft Domain-Specific Language tools, https://msdn.microsoft. com/en-us/library/bb126327.aspx, [Accessed 20 October 2017]. 
[30] Eclipse Modeling Framework (EMF), https://www.eclipse.org/ modeling/emf/, [Accessed 20 October 2017].

[31] J. Bézivin, G. Hillairet, F. Jouault, I. Kurtev, W. Piers, Bridging the MS/DSL Tools and the Eclipse Modeling Framework, in: In Proceedings of the International Workshop on Software Factories at OOPSLA 2005, 2005.

[32] G. Hinkel, T. Goldschmidt, E. Burger, R. Reussner, Using Internal DomainSpecific Languages to inherit Tool Support and Modularity for Model Transformations, Software \& Systems Modeling (2017) 1-27doi:10.1007/ s10270-017-0578-9.

[33] R. B. Salem, R. Grangel, J.-P. Bourey, A comparison of model transformation tools: Application for Transforming GRAI Extended Actigrams into UML Activity Diagrams, Computers in Industry" 59 (7) (2008) 682-693. doi:https://doi.org/10.1016/j.compind.2007.12.013

[34] D. Chen, G. Doumeingts, The GRAI-GIM reference model, architecture and methodology, in: P. Bernus, L. Nemes, T. Williams (Eds.), In Architectures for Enterprise Integration, Springer US, 1996, pp. 102-126. doi:10.1007/978-0-387-34941-1_7

[35] K. Kosanke, F. Vernadat, M. Zelm, CIMOSA process model for enterprise modelling, in: J. Goossenaerts, F. Kimura, H. Wortmann (Eds.), In Information Infrastructure Systems for Manufacturing: Proceedings of the IFIP TC5/WG5.3/WG5.7 international conference on the Design of Information Infrastructure Systems for Manufacturing, DIISM '96 Eindhoven, the Netherlands, 15-18 September 1996, Springer US, 1997, pp. 59-68.

[36] C. C. O. C. R. Grangel, R. Chalmeta, Enterprise Modelling, an overview focused on software generation, in: In Interoperability of ESA Workshops of the INTEROP-ESA International Conference EI2N, WSI, ISIDI and IEHENA, 2005, pp. 65-76. 
[37] INTEROP, Interoperability Research for Networked Enterprises Applications and Software NoE (IST-2003-508011), http://interop-vlab.eu/, [Accessed 20 October 2017].

[38] R. Grangel, R. Chalmeta, S. Schuster, I. Peña, Exchange of Business Process Models using the POP* Meta-model, in: In International Workshop on Enterprise and Networked Enterprises Interoperability (ENEI'2005), Vol. 3812/2005 of Lecture Notes in Computer Science, Springer-Verlag, 2005.

[39] A.-J. Berre, et al., The ATHENA Interoperability Framework, in: R. J. Gonçalves, J. P. Müller, K. Mertins, M. Zelm (Eds.), Enterprise Interoperability II: New Challenges and Approaches, Springer London, 2007, pp. 569-580. doi:10.1007/978-1-84628-858-6_62.

[40] W. Engelsman, D. Quartel, H. Jonkers, M. van Sinderen, Extending enterprise architecture modelling with business goals and requirements, Enterprise Information Systems 5 (1) (2011) 9-36.

[41] Enterprise Architecture at Work: Modelling, Communication and Analysis, 4th Edition, Springer, 2017.

[42] M. J. Epstein, A. R. Buhovac, Making sustainability work: Best practices in managing and measuring corporate social, environmental, and economic impacts, Berrett-Koehler Publishers, 2014.

[43] T. Mens, P. van Gorp, A Taxonomy of Model Transformation, Electronic Notes in Theoretical Computer Science 152 (2006) 125-142.

[44] K. Czarnecki, S. Helsen, Classification of model transformation approaches, in: Proceedings of the 2nd OOPSLA Workshop on Generative Techniques in the Context of the Model Driven Architecture, Vol. 45, 2003, pp. 1-17.

910 [45] E. Seidewitz, What Models Mean, IEEE Software 20 (5) (2003) 26-32. doi: http://doi.ieeecomputersociety.org/10.1109/MS.2003.1231147. 
[46] I. García-Magariño, R. Fuentes-Fernández, J. Gómez-Sanz, A framework for the definition of metamodels for Computer-Aided Software Engineering tools, Information and Software Technology 52 (4) (2010) 422-435.

[47] R. Grangel, R. Chalmeta, C. Campos, A Modelling Framework for Sharing Knowledge, in: B. Apolloni, R. J. Howlett, L. Jain (Eds.), In KnowledgeBased Intelligent Information and Engineering Systems: 11th International Conference, KES 2007, XVII Italian Workshop on Neural Networks, Vietri sul Mare, Italy, September 12-14, 2007. Proceedings, Part II, Springer Berlin Heidelberg, 2007, pp. 1230-1237.

[48] G. Pépiot, N. Cheikhrouhou, J.-M. Furbringer, R. Glardon, UECML: Unified Enterprise Competence Modelling Language, Computers in Industry 58 (2) (2007) 130-142.

[49] R. Grangel, R. Chalmeta, C. Campos, Using UML Profiles for Enterprise Knowledge Modelling, in: In 2007 Eleventh International IEEE EDOC Conference Workshop, 2007.

[50] A. Maté, J. Trujillo, A trace metamodel proposal based on the model driven architecture framework for the traceability of user requirements in data warehouses, Information Systems 37 (8) (2012) 753-766.

[51] G. Zoughbi, L. Briand, Y. Labiche, Modeling safety and airworthiness (RTCA DO-178B) information: conceptual model and UML profile, Software \& Systems Modeling 10 (3) (2011) 337-367.

[52] A. Martínez-García, J. A. García-García, M. J. Escalona, C. L. ParraCalderón, Working with the HL7 metamodel in a Model Driven Engineering context, Journal of Biomedical Informatics 57 (2015) 415-424.

[53] A. Marques-Mendes, M. J. Santos, Strategic CSR: an integrative model for analysis, Social Responsibility Journal 12 (2) (2016) 363-381. doi: 10.1108/SRJ-04-2015-0055. 
[54] M. Pankowska, Enterprise Architecture Modelling for Corporate Sustainability, in: H. L. et al. (Ed.), Building Sustainable Information Systems: Proceedings of the 2012 International Conference on Information Systems Development, Springer US, 2013, pp. 365-376. doi:10.1007/ 978-1-4614-7540-8_28.

[55] K. Pohl, Requirements Engineering. Fundamentals, Principles, and Techniques, Springer, 2010.

[56] R. S. Pressman, B. R. Maxim, Software Engineering: A Practitioner's Approach, McGraw-Hill, 2015.

[57] A. McWilliams, D. S. Siegel, P. M. Wright, Corporate Social Responsibility: Strategic Implications, Journal of Management Studies 43 (1) (2006) 1-18.

[58] C. Campos, R. Grangel, R. Chalmeta, O. Coltell, Requirements to Improve the Synchronisation of Inter-enterprise Models, in: C. Bussler, A. Haller (Eds.), Business Process Management Workshops, Vol. 3812 of Lecture Notes in Computer Science, Springer Berlin Heidelberg, 2006, pp. 353-362. doi:10.1007/11678564_31.

[59] R. Grangel, R. Chalmeta, C. Campos, Defining of Target Knowledge in Virtual Enterprise, in: W. Abramowicz, H. C. Mayr (Eds.), In Business Information Systems - 9th International Conference on Business Information Systems (BIS 2006), Vol. 85 of LNI, Gesellschaft fr Informatik (GI), 2006.

[60] R. Baskerville, M. D. Myers, Special issue on action research in information systems: making IS research relevant to practice-foreword, MIS Quarterly 28 (3) (2004) 329-335.

[61] J. Elkington, Cannibals With Forks: The Triple Bottom Line of 21st Century Business.

[62] H. S. Browna, M. de Jongb, D. L. Levycuilding, Building Institutions based on Information Disclosure: Lessons from GRIs Sustainability Reporting, Journal of Cleaner Production 17 (6) (2009) 571-580. 
[63] ISO 9000:2015, Quality management systems, Tech. rep., ISO, [Accessed 20 October 2017] (2015).

[64] R. Hahn, ISO 26000 and the Standardization of Strategic Management Processes for Sustainability and Corporate Social Responsibility, Business Strategy and the Environment 22 (7) (2013) 442-455. doi:10.1002/bse. 1751 .

[65] H. Wang, L. Tong, R. Takeuchi, G. George, Corporate Social Responsibility: An Overview and New Research Directions: Thematic Issue on Corporate Social Responsibility, Academy of Management Journal 59 (2) (2016) 534-544.

[66] M. Weber, The business case for corporate social responsibility: A company-level measurement approach for CSR, European Management Journal 26 (4) (2008) 247-261.

[67] M. O'Connor, J. H. Spangenberg, A methodology for CSR reporting: assuring a representative diversity of indicators across stakeholders, scales, sites and performance issues, Journal of Cleaner Production 16 (13) (2008) $139-1415$.

[68] Z.-Y. Zhao, X.-J. Zhao, K. Davidson, J. Zuo, A corporate social responsibility indicator system for construction enterprises, Journal of Cleaner Production 2930 (2012) 277-289.

[69] L. Schmeltz, Getting CSR communication fit: A study of strategically fitting cause, consumers and company in corporate CSR communication, Public Relations Inquiry 6 (1) (2017) 47-72.

[70] Responsible Research and Innovation Section (RRI). European Commis口. sion Horizon 2020, https://ec.europa.eu/programmes/horizon2020/ en/h2020-section/responsible-research-innovation, [Accessed 20 October 2017]. 
[71] MSCIs research-based indexes. The Global Industry Classification Standard (GICS), Tech. rep., [Accessed 20 October 2017].

[72] Coca-Cola Sustainability, http://www.coca-colacompany.com/ sustainability, [Accessed 20 October 2017].

[73] Inditex Sustainability, https://www.inditex.com/en/sustainability, [Accessed 20 October 2017].

[74] Starbucks. Being a Responsible Company, http://www.starbucks.ph/ responsibility, [Accessed 20 October 2017].

[75] McDonalds Sustainability, http://corporate.mcdonalds.com/content/ mcd/sustainability.html, [Accessed 20 October 2017].

[76] Valencia Open. Corporate Social Responsibility Plan, http://www. valenciaopen.tennis/en/rsc, [Accessed 20 October 2017].

[77] ICRC International Committee of The Red Cross, https://www.icrc. org/, [Accessed 20 October 2017].

[78] Suppressed for blinded review (2017).

[79] MagicDraw (No Magic), https://www.nomagic.com/products/ magicdraw, [Accessed 20 October 2017].

[80] Madebyoliver, Icons made by Madebyoliver from www.flaticon.com, http: //www.flaticon.com/packs/essential-set-2/4, [Accessed 20 October 2017].

[81] P. Laforcade, A Domain-Specific Modeling approach for supporting the specification of Visual Instructional Design Languages and the building of dedicated editors, Journal of Visual Languages \& Computing 21 (6) (2010) 347-358. doi:http://dx.doi.org/10.1016/j.jvlc.2010.08.008

[82] R. K. Yin, Case Study Research: Design and Methods (Applied Social Research Methods), SAGE Publications, Inc, 2014. 
1020 [83] Pamesa Group Sustainability, https://www.pamesa.com/corporate/ sustainability/environment/s69, [Accessed 20 October 2017].

[84] M. K. Sein, O. Henfridsson, S. Purao, M. Rossi, R. Lindgren, Action Design Research, MIS Quarterly 35 (1) (2011) 37-56. 